\title{
Impact of exact segment by segment primary tumor location status on anti-EGFR antibody first-line treatment efficacy in RAS/BRAF wild-type and BRAF mutant metastatic colorectal cancer. A pooled analysis of AIO studies FIRE-1, CIOX, FIRE-3, XELAVIRI, and VOLFI.
}

\section{Annabel Helga Sophie Alig}

Charite Universitatsmedizin Berlin Campus Charite Mitte: Charite Universitatsmedizin Berlin https://orcid.org/0000-0002-3922-3450

\section{Volker Heinemann}

Klinikum der Universitat Munchen Campus Grosshadern: Klinikum der Universitat Munchen Standort Grosshadern

\section{Michael Geissler}

Stadtisches Klinikum Karlsruhe gGmbH

\section{Ludwig Fischer von Weikersthal}

Gesundheitszentrum St. Marien, Amberg

\section{Thomas Decker}

Oncological Practice, Ravensburg

Kathrin Heinrich

Klinikum der Universitat Munchen Campus Grosshadern: Klinikum der Universitat Munchen Standort Grosshadern

\section{Swantje Held}

ClinAssess GmbH, Leverkusen

\section{Lena Weiss}

Klinikum der Universitat Munchen Campus Grosshadern: Klinikum der Universitat Munchen Standort Grosshadern

\section{Laura Elisabeth Fischer}

Klinikum der Universitat Munchen Campus Grosshadern: Klinikum der Universitat Munchen Standort Grosshadern

\section{Nicolas Moosmann}

Krankenhaus Barmherzige Bruder Regensburg

\section{Arndt Stahler}

Charite Universitatsmedizin Berlin Campus Charite Mitte: Charite Universitatsmedizin Berlin 


\section{Ivan Jelas}

Charite Universitatsmedizin Berlin Campus Charite Mitte: Charite Universitatsmedizin Berlin

\section{Annika Kurreck}

Charité Universitätsmedizin Berlin CVK: Charite Universitatsmedizin Berlin - Campus Virchow-Klinikum Jana Kaethe Striefler

Charité Universitätsmedizin Berlin CVK: Charite Universitatsmedizin Berlin - Campus Virchow-Klinikum Jobst Christian von Einem

Charite Universitatsmedizin Berlin Campus Charite Mitte: Charite Universitatsmedizin Berlin

\section{Anke Claudia Reinacher-Schick}

Saint Josef Hospital: Sankt Josef Krankenhaus

\section{Andrea Tannapfel}

Universitatsklinikum der Ruhr-Universitat Bochum

\section{Clemens Giessen-Jung}

University Hospital Munich Campus Grosshadern: Klinikum der Universitat Munchen Standort Grosshadern

\section{Sebastian Stintzing}

Charite Universitatsmedizin Berlin Campus Charite Mitte: Charite Universitatsmedizin Berlin

Dominik Paul Modest ( $\nabla$ dominik.modest@charite.de)

Charité University Medicine Berlin

\section{Research}

Keywords: primary tumor location, metastatic colorectal cancer, EGFR antibody, RAS wildtype, BRAF mutation

Posted Date: February 24th, 2021

DOI: https://doi.org/10.21203/rs.3.rs-219007/v1

License: (c) (i) This work is licensed under a Creative Commons Attribution 4.0 International License. Read Full License 


\section{Abstract}

\section{Background}

Primary tumor location (left vs. right) has prognostic and predictive impact on the therapeutic management of metastatic colorectal cancer (mCRC) in particular in the context of anti-epithelial growth factor receptor (anti-EGFR) antibodies.

This analysis evaluates the relevance of exact segment-by-segment tumor location in patients with metastatic colorectal cancer on outcome and efficacy of anti-EGFR-antibodies.

\section{Methods}

This is a retrospective, pooled analysis of five randomized clinical trials (FIRE-1, CIOX, FIRE-3, XELAVIRI and VOLFI) treating metastatic colorectal cancer patients in a first-line setting, published between 20112019. Each trial was a multicentre, phase 2 or phase 3 trial in which patients with untreated metastatic colorectal cancer received chemotherapy regimens with or without monoclonal antibodies (anti-VEGF, anti-EGFR). Eligible were patients with histologically confirmed metastatic colorectal cancer in good performance status who were at least 18 years old. Individual data of 1809 patients with available exact primary tumor location were included into this analysis.

Prognostic and predictive effects of primary tumor location were evaluated in uni- and multivariate analyses using the Kaplan Meier method, log rank tests, Cox regressions and logistic regressions

\section{Results}

Exact primary tumor location is an important determinant of overall survival (OS) in mCRC patients $(P<0.001)$. Multivariate analysis of RAS/BRAF wild-type metastatic colorectal cancer indicate that efficacy of anti-EGFR agents in terms of OS increases continuously from primary tumors located in the caecum (HR 2.63), ascending colon (HR 1.24), right flexure/transverse colon (HR 0.99), left flexure/descending colon (HR 0.91) to the sigmoid (HR 0.71) and rectum (HR 0.58), demonstrating significant benefit in sigmoid and rectal metastatic colorectal cancer, as well as clear detriment in caecum mCRC. Patients with BRAF V600E mutant disease arising from left-sided segments of the colorectum benefitted from EGFR-antibody treatment survival: hazard ratio for death in left-sided tumors: 0.42 (95\% Cl 0.19-0.92).

\section{Conclusions}

Primary tumor location of metastatic colorectal cancer affects prognosis. Anti-EGFR efficacy increases continuously from proximal to distal segments of the colorectum in metastatic colorectal cancer patients with RAS/BRAF wild-type and BRAF mutant tumors. Therefore, patients with BRAF mutant tumors of the distal segments may benefit from first-line Anti-EGFR-based therapy.

\section{Trial registration}


FIRE1 trial registration ID n/a

CIOX trial registration ID NCT00254137

FIRE3 trial registration ID NCT00433927

XELAVIRI trial registration ID NCT01249638

VOLFI trial registration ID NCT01328171

\section{Background}

Primary tumor location (PTL), usually defined as left- vs. right with a cut-off at the splenic flexure, is a prognostic and predictive biomarker in the treatment of metastatic colorectal cancer (mCRC) [1-4]. Patients presenting with right-sided $\mathrm{mCRC}$ have a dismal prognosis as compared to patients with leftsided mCRC. Additionally the PTL also appears to predict the efficacy of antibodies targeting the epidermal growth factor receptor (EGFR) with patients presenting with left-sided mCRC deriving a substantial benefit in overall survival (OS) with cetuximab or panitumumab therapy [1, 2].

Numerous efforts have been made to find a clear molecular correlate of clinical observations that have established primary tumor location as a tool for clinical decision-making. Although various molecular factors occurring with differing frequencies throughout the colon and rectum can be described [5-9], a usable classifier still has to be established. A key problem in the development of a molecular-based "rightvs- left mCRC" classifier might be that clear cut-offs cannot be found for most molecular markers and the biology of molecular differences throughout the colorectum underlies rather continuous changes than dichotomous distributions $[6,10]$.

Therefore, this pooled analysis of five randomized trials evaluates the impact of the exact location of the primary tumor (i.e. caecum, ascending colon, right flexure plus transverse colon, left flexure plus descending colon, sigmoid and rectum) in patients with mCRC breaking up the dichotomy of left- vs. right-sided colorectal cancer into six subgroups, acknowledging the continuum hypothesis [10]. We ask the question to which extent the exact location influences the prognosis also taking into account molecular subgroups as defined by (K)RAS and BRAF mutations. Moreover, the effect of anti-EGFR treatment according to exact PTL is explored in patients with RAS/BRAF wildtype and BRAF V600E mutant mCRC.

As this investigation is a retrospective and unplanned analysis our findings should be interpreted as such.

\section{Methods}

Trials 
We performed a retrospective analysis of five trials addressing patients with previously untreated $\mathrm{mCRC}$. Reports of the trials have been published previously [11-21]. All trials were conducted according to the Declaration of Helsinki and were approved by ethics committees. Table 1 provides an overview of the included studies. 
Table 1

characteristics of the five studies included in the pooled analysis

\begin{tabular}{|c|c|c|c|c|c|}
\hline & $\begin{array}{l}\text { FIRE-1 } \\
{[11,17]}\end{array}$ & $\begin{array}{l}\text { CIOX } \\
{[14,16]}\end{array}$ & $\begin{array}{l}\text { FIRE-3 } \\
{[12,18-21]}\end{array}$ & $\begin{array}{l}\text { XELAVIRI } \\
\text { [13] }\end{array}$ & $\begin{array}{l}\text { VOLFI } \\
\text { [15] }\end{array}$ \\
\hline Phase of study & III & II & III & III & II \\
\hline Country & Germany & Germany & $\begin{array}{l}\text { Germany / } \\
\text { Austria }\end{array}$ & Germany & Germany \\
\hline No. of centers & 48 & 35 & $110 / 6$ & 82 & 21 \\
\hline $\begin{array}{l}\text { Recruiting } \\
\text { period }\end{array}$ & $\begin{array}{l}07 / 2000- \\
10 / 2004\end{array}$ & $\begin{array}{l}09 / 2004- \\
12 / 2006\end{array}$ & $\begin{array}{l}01 / 2007- \\
09 / 2012\end{array}$ & $\begin{array}{l}\text { 12/2010- } \\
04 / 2016\end{array}$ & $\begin{array}{l}\text { 06/2011- } \\
01 / 2016\end{array}$ \\
\hline $\begin{array}{l}\text { Primary } \\
\text { endpoint }\end{array}$ & PFS & ORR & ORR & TFS & ORR \\
\hline $\begin{array}{l}\text { Overall survival } \\
\text { censored (\%) }\end{array}$ & 12.9 & 19.8 & 12.7 & 15.2 & 34.4 \\
\hline $\begin{array}{l}\text { treatment arms } \\
\operatorname{arm~A}\end{array}$ & FUFIRI & CAPIRI + Cet & FOLFIRI + Cet & $\begin{array}{l}\mathrm{FP}+\mathrm{Bev}->\mathrm{PD} \\
->\mathrm{FP}+\mathrm{Iri}+ \\
\mathrm{Bev}\end{array}$ & $\begin{array}{l}\text { mFOLFOXIRI } \\
+ \text { Pani }\end{array}$ \\
\hline arm B & mIROX & CAPOX + Cet & FOLFIRI + Bev & $\mathrm{FP}+\mathrm{Iri}+\mathrm{Bev}$ & FOLFOXIRI \\
\hline $\begin{array}{l}\text { Molecular } \\
\text { subgroup } \\
\text { allowed }\end{array}$ & all & all & $\begin{array}{l}\text { All; KRAS exon } \\
2 \\
\text { after } 2009\end{array}$ & all & $\begin{array}{l}\text { KRAS exon } 2 \\
\text { WT, } \\
\text { RAS WT from } \\
2014\end{array}$ \\
\hline $\begin{array}{l}\text { Previous } \\
\text { adjuvant } \\
\text { chemotherapy } \\
\text { allowed }\end{array}$ & $\begin{array}{l}\text { yes (no } \\
\text { TOP1 } \\
\text { inhibitors, } \\
\text { no } \\
\text { platinum) }\end{array}$ & $\begin{array}{l}\text { yes (no TOP1 } \\
\text { inhibitors) }\end{array}$ & yes & yes & yes \\
\hline $\begin{array}{l}\text { Time between } \\
\text { end of } \\
\text { adjuvant } \\
\text { therapy and } \\
\text { relapse, } \\
\text { months }\end{array}$ & 6 & 6 & 6 & 6 & 6 \\
\hline RECIST version & - (WHO) & 1.0 & 1.0 & 1.1 & 1.1 \\
\hline $\begin{array}{l}\text { Trial finder } \\
\text { registration }\end{array}$ & - & NCT00254137 & NCT00433927 & NCT01249638 & NCT01328171 \\
\hline
\end{tabular}




\begin{tabular}{|llllll|}
\hline & FIRE-1 & CIOX & FIRE-3 & XELAVIRI & VOLFI \\
& {$[11,17]$} & {$[14,16]$} & {$[12,18-21]$} & {$[13]$} & {$[15]$} \\
\hline $\begin{array}{l}\text { Eligibility } \\
\text { criteria }\end{array}$ & $18-75$ & $18-75$ & $18-75$ & $\geq 18$ & $\geq 18$ \\
Age, years & - & - & $\leq 2$ & $\leq 1$ & $\leq 1$ \\
$\begin{array}{l}\text { ECOG } \\
\begin{array}{l}\text { Karnowsky } \\
\text { index }\end{array}\end{array}$ & $\geq 70 \%$ & $\geq 70 \%$ & - & - & - \\
\hline
\end{tabular}

Patients An anonymized clinical database of the trials was established including the following information for each patient: trial, treatment arm, use of EGFR-antibody, age, sex, ECOG performance status, tumor characteristics (exact primary tumor site, metastatic sites), prior adjuvant treatment, molecular characteristics ((K)RAS and BRAF mutational status). Tumor samples assigned to each patient were tested for (K)RAS- and BRAF V600E-mutations as described previously [12-20].

\section{Exact primary tumor location}

Locations of the primary were extracted from the respective study report forms and differentiated into caecum, ascending colon, right flexure, transverse colon, left flexure, descending colon, sigmoid and rectum. Due to small numbers, tumors of the right flexure and transverse colon were analyzed as one group as well as tumors originating from the left flexure and the descending colon. Patients with more than one primary in more than one of these segments were excluded from the analysis of exact primary tumor location. Patients with tumors of the recto-sigmoid region were analyzed as sigmoid carcinoma.

\section{Treatment}

Treatment procedures were described in detail in the previous publications and are summarized in Table 1. Details concerning dosages are displayed in supplementary table 1. Treatments were stratified according to anti-EGFR antibody use vs. chemotherapy alone or bevacizumab-based therapy.

\section{Definition of progression-free survival and overall survival}

Progression-free survival (PFS) was defined as time from randomisation to first progression of disease or death from any cause (whatever occurred first). In addition, the XELAVIRI study defined PFS as time from randomisation until switching to a new anticancer drug. Overall survival (OS) was defined as time from randomisation to death from any cause. Objective response (OR) was evaluated according to classifications of the WHO (FIRE-1), RECIST 1.0 (CIOX, FIRE-3) or RECIST 1.1 (XELAVIRI, VOLFI).

\section{Statistical analysis}

All statistical analyses were performed using SAS software (version 9.4; SAS Institute, Cary, NC) and SPSS version 25.0 software (IBM Corporation, Amonk, NY, USA). Survival was expressed as medians including 95\% confidence intervals by Kaplan Meier method and compared using log-rank tests. 
Univariate and multivariate Cox regression analyses were used to conduct subgroup analyses.

Additionally, Cox regression analyses with maximum-likelihood estimation were used for interaction testing. The two-sided significance level was set to 0.05 and estimates are reported with $95 \%$ confidence intervals.

\section{Results}

\section{Patient and tumor characteristics}

The study population consists of a total of 1809 patients with known exact primary tumor location, including 1333 patients with known molecular characteristics (of those: 717 patients with RAS/BRAF wildtype tumors, 514 patients with RAS mutant tumors, 102 patients with BRAF V600E mutant tumors). An overview of contributing studies and frequency of each location is shown in Supplementary Fig. 1. Baseline characteristics of patients and tumors are summarized in Table 2. Several characteristics are significantly associated with the exact PTL. Of note, the frequency of BRAF mutations ranged from 10$20 \%$ among the characterized tumor specimens in the right-sided locations, whereas only approximately $3 \%$ of sigmoid and rectal specimens harboured such a mutation. In contrast, the frequency of RAS mutations is also pronounced in right-sided tumors and appears to decrease from right to left, but peaking again in rectal tumors. A graphical overview of baseline and tumor characteristics of interest with significant differences according to exact PTL is provided as supplementary Fig. 2. 
Table 2

Patient and tumor characteristics

characteristic

Study

FIRE-1

CIOX

FIRE-3

XELAVIRI

VOLFI

$$
30
$$$$
\text { (19.0\%) (13.4\%) }
$$

$\begin{array}{ll}21 & 21 \\ (13.3 \%) & (11.3 \%)\end{array}$

51

51
$(32.3 \%)$

90

$(48.4 \%)$

$\begin{array}{ll}47 & 47 \\ (29.7 \%) & (25.3 \%)\end{array}$

$9(5.7 \%)$

$27(25.2 \%)$

$12(11.2 \%)$

$30(28.0 \%)$

$33(30.8 \%)$

R. flexure + C. trans.

$(n=107)$

$12(11.2 \%)$

$5(4.7 \%)$
L. flexure + C. desc.

$(n=126)$

$(n=520)$
Rectum

Sigmoid

Rectum $(n=712)$

\section{RAS/BRAF status}

\begin{tabular}{|c|c|c|c|c|c|c|}
\hline RAS/BRAF WT & $\begin{array}{l}40 \\
(25.3 \%)\end{array}$ & $\begin{array}{l}60 \\
(32.3 \%)\end{array}$ & 37 (34.6\%) & 54 (42.9\%) & $\begin{array}{l}250 \\
(48.1 \%)\end{array}$ & $\begin{array}{l}276 \\
(38.8 \%)\end{array}$ \\
\hline RAS MT & $\begin{array}{l}67 \\
(42.4 \%)\end{array}$ & $\begin{array}{l}60 \\
(32.3 \%)\end{array}$ & $30(28.0 \%)$ & 36 (28.6\%) & $\begin{array}{l}102 \\
(19.6 \%)\end{array}$ & $\begin{array}{l}219 \\
(30.8 \%)\end{array}$ \\
\hline BRAF MT & $\begin{array}{l}14 \\
(8.9 \%)\end{array}$ & $\begin{array}{l}25 \\
(13.4 \%)\end{array}$ & $16(15.0 \%)$ & $11(8.7 \%)$ & $\begin{array}{l}15 \\
(2.9 \%)\end{array}$ & $\begin{array}{l}21 \\
(2.9 \%)\end{array}$ \\
\hline unknown & $\begin{array}{l}37 \\
(23.4 \%)\end{array}$ & $\begin{array}{l}41 \\
(22.0 \%)\end{array}$ & $24(22.4 \%)$ & 25 (19.8\%) & $\begin{array}{l}153 \\
(29.4 \%)\end{array}$ & $\begin{array}{l}196 \\
(27.5 \%)\end{array}$ \\
\hline \multicolumn{7}{|l|}{ Antibody } \\
\hline none & $\begin{array}{l}33 \\
(20.9 \%)\end{array}$ & $\begin{array}{l}28 \\
(15.1 \%)\end{array}$ & 29 (27.1\%) & 34 (27.0\%) & $\begin{array}{l}135 \\
(26.0 \%)\end{array}$ & $\begin{array}{l}196 \\
(27.5 \%)\end{array}$ \\
\hline anti-EGFR & $\begin{array}{l}51 \\
(32.3 \%)\end{array}$ & $\begin{array}{l}62 \\
(33.3 \%)\end{array}$ & 27 (25.2\%) & $44(34.9 \%)$ & $\begin{array}{l}184 \\
(35.4 \%)\end{array}$ & $\begin{array}{l}236 \\
(33.1 \%)\end{array}$ \\
\hline anti-VEGF & $\begin{array}{l}74 \\
(46.8 \%)\end{array}$ & $\begin{array}{l}96 \\
(51.6 \%)\end{array}$ & $51(47.7 \%)$ & 48 (38.1\%) & $\begin{array}{l}201 \\
(38.7 \%)\end{array}$ & $\begin{array}{l}280 \\
(39.3 \%)\end{array}$ \\
\hline
\end{tabular}

\section{Sex}

male

female

\begin{tabular}{ll}
92 & 123 \\
$(58.2 \%)$ & $(66.1 \%)$ \\
\hline 66 & 63 \\
$(41.8 \%)$ & $(33.9 \%)$ \\
\hline
\end{tabular}

$65(60.7 \%)$

$88(69.8 \%)$

347

$(66.7 \%) \quad(73.5 \%)$

$42(39.3 \%)$

$38(30.2 \%)$

173

(33.3\%)

189

(26.5\%) 


\begin{tabular}{|c|c|c|c|c|c|c|}
\hline characteristic & Caecum & C. asc. & $\begin{array}{l}\text { R. flexure + C. } \\
\text { trans. }\end{array}$ & $\begin{array}{l}\text { L. flexure +C. } \\
\text { desc. }\end{array}$ & Sigmoid & Rectum \\
\hline $\begin{array}{l}\text { Age (years) } \\
\text { Median (range) }\end{array}$ & $\begin{array}{l}65(31- \\
87)\end{array}$ & $\begin{array}{l}67(32- \\
84)\end{array}$ & $66(22-88)$ & $66(25-84)$ & $\begin{array}{l}64(32- \\
81)\end{array}$ & $\begin{array}{l}64(27- \\
86)\end{array}$ \\
\hline$\leq 60$ & $\begin{array}{l}50 \\
(31.6 \%)\end{array}$ & $\begin{array}{l}53 \\
(28.5 \%)\end{array}$ & 25 (23.4\%) & 38 (30.2\%) & $\begin{array}{l}191 \\
(36.7 \%)\end{array}$ & $\begin{array}{l}261 \\
(36.7 \%)\end{array}$ \\
\hline$>60-\leq 70$ & $\begin{array}{l}63 \\
(39.9 \%)\end{array}$ & $\begin{array}{l}75 \\
(40.3 \%)\end{array}$ & 45 (42.1\%) & 54 (42.9\%) & $\begin{array}{l}209 \\
(40.2 \%)\end{array}$ & $\begin{array}{l}296 \\
(41.6 \%)\end{array}$ \\
\hline$>70$ & $\begin{array}{l}45 \\
(28.5 \%)\end{array}$ & $\begin{array}{l}58 \\
(31.2 \%)\end{array}$ & 37 (34.6\%) & 34 (27.0\%) & $\begin{array}{l}120 \\
(23.1 \%)\end{array}$ & $\begin{array}{l}155 \\
(29.8 \%)\end{array}$ \\
\hline \multicolumn{7}{|l|}{ ECOG } \\
\hline 0 & $\begin{array}{l}98 \\
(62.0 \%)\end{array}$ & $\begin{array}{l}95 \\
(51.1 \%)\end{array}$ & 57 (53.3\%) & 65 (51.6\%) & $\begin{array}{l}321 \\
(61.7 \%)\end{array}$ & $\begin{array}{l}449 \\
(63.0 \%)\end{array}$ \\
\hline 1 & $\begin{array}{l}53 \\
(33.5 \%)\end{array}$ & $\begin{array}{l}78 \\
(41.9 \%)\end{array}$ & $46(43.0 \%)$ & 54 (42.9\%) & $\begin{array}{l}179 \\
(34.4 \%)\end{array}$ & $\begin{array}{l}234 \\
(32.9 \%)\end{array}$ \\
\hline 2 & $7(4.4 \%)$ & $\begin{array}{l}13 \\
(7.0 \%)\end{array}$ & $4(3.7 \%)$ & $5(4.0 \%)$ & $\begin{array}{l}18 \\
(3.5 \%)\end{array}$ & $\begin{array}{l}25 \\
(3.5 \%)\end{array}$ \\
\hline unknown & $0(0 \%)$ & $0(\%)$ & $0(0 \%)$ & $2(1.6 \%)$ & $2(0.4 \%)$ & $4(5.6 \%)$ \\
\hline \multicolumn{7}{|l|}{$\begin{array}{l}\text { Metastatic } \\
\text { spread }\end{array}$} \\
\hline liver & $\begin{array}{l}122 \\
(77.2 \%)\end{array}$ & $\begin{array}{l}145 \\
(78.0 \%)\end{array}$ & 89 (83.2\%) & 107 (85.0\%) & $\begin{array}{l}450 \\
(86.5 \%)\end{array}$ & $\begin{array}{l}527 \\
(74.1 \%)\end{array}$ \\
\hline liver-limited & $\begin{array}{l}54 \\
(34.2 \%)\end{array}$ & $\begin{array}{l}56 \\
(30.1 \%)\end{array}$ & 40 (37.4\%) & $58(46.0 \%)$ & $\begin{array}{l}199 \\
(38.3 \%)\end{array}$ & $\begin{array}{l}219 \\
(30.8 \%)\end{array}$ \\
\hline lung & $\begin{array}{l}53 \\
(33.5 \%)\end{array}$ & $\begin{array}{l}63 \\
(33.9 \%)\end{array}$ & 29 (27.1\%) & $28(22.2 \%)$ & $\begin{array}{l}165 \\
(31.7 \%)\end{array}$ & $\begin{array}{l}328 \\
(46.1 \%)\end{array}$ \\
\hline lymph nodes & $\begin{array}{l}51 \\
(32.3 \%)\end{array}$ & $\begin{array}{l}77 \\
(41.4 \%)\end{array}$ & 39 (36.4\%) & $28(22.2 \%)$ & $\begin{array}{l}139 \\
(26.7 \%)\end{array}$ & $\begin{array}{l}190 \\
(26.7 \%)\end{array}$ \\
\hline peritoneum & $\begin{array}{l}24 \\
(15.2 \%)\end{array}$ & $\begin{array}{l}15 \\
(8.1 \%)\end{array}$ & $9(8.4 \%)$ & $10(7.9 \%)$ & $\begin{array}{l}35 \\
(6.7 \%)\end{array}$ & $\begin{array}{l}18 \\
(2.5 \%)\end{array}$ \\
\hline \multicolumn{7}{|c|}{$\begin{array}{l}\text { No. of metastatic } \\
\text { sites }\end{array}$} \\
\hline 1 & $\begin{array}{l}69 \\
(43.7 \%)\end{array}$ & $\begin{array}{l}76 \\
(40.9 \%)\end{array}$ & 47 (44.0\%) & 68 (54.0\%) & $\begin{array}{l}222 \\
(42.7 \%)\end{array}$ & $\begin{array}{l}296 \\
(41.6 \%)\end{array}$ \\
\hline 2 & $\begin{array}{l}43 \\
(27.2 \%)\end{array}$ & $\begin{array}{l}65 \\
(34.9 \%)\end{array}$ & 30 (28.0\%) & 34 (27.0\%) & $\begin{array}{l}162 \\
(31.2 \%)\end{array}$ & $\begin{array}{l}227 \\
(31.9 \%)\end{array}$ \\
\hline 3 & $\begin{array}{l}22 \\
(13.9 \%)\end{array}$ & $\begin{array}{l}27 \\
(14.5 \%)\end{array}$ & $18(16.8 \%)$ & $13(10.3 \%)$ & $\begin{array}{l}68 \\
(13.1 \%)\end{array}$ & $\begin{array}{l}113 \\
(15.9 \%)\end{array}$ \\
\hline
\end{tabular}




\begin{tabular}{|c|c|c|c|c|c|c|}
\hline characteristic & Caecum & C. asc. & $\begin{array}{l}\text { R. flexure + C. } \\
\text { trans. }\end{array}$ & $\begin{array}{l}\text { L. flexure + C. } \\
\text { desc. }\end{array}$ & Sigmoid & Rectum \\
\hline$\geq 4$ & $\begin{array}{l}10 \\
(6.3 \%)\end{array}$ & $\begin{array}{l}12 \\
(6.5 \%)\end{array}$ & $4(3.7 \%)$ & $4(3.2 \%)$ & $\begin{array}{l}23 \\
(4.4 \%)\end{array}$ & $\begin{array}{l}29 \\
(4.1 \%)\end{array}$ \\
\hline unknown & $\begin{array}{l}14 \\
(8.9 \%)\end{array}$ & $6(3.2 \%)$ & $8(7.5 \%)$ & $7(5.6 \%)$ & $\begin{array}{l}45 \\
(8.7 \%)\end{array}$ & $\begin{array}{l}47 \\
(6.6 \%)\end{array}$ \\
\hline \multicolumn{7}{|l|}{$\begin{array}{l}\text { Onset of } \\
\text { metastases }\end{array}$} \\
\hline synchronous & $\begin{array}{l}97 \\
(61.4 \%)\end{array}$ & $\begin{array}{l}130 \\
(69.9 \%)\end{array}$ & $62(58.0 \%)$ & 79 (62.7\%) & $\begin{array}{l}321 \\
(61.7 \%)\end{array}$ & $\begin{array}{l}395 \\
(55.5 \%)\end{array}$ \\
\hline metachronous & $\begin{array}{l}30 \\
(19.0 \%)\end{array}$ & $\begin{array}{l}31 \\
(16.7 \%)\end{array}$ & 27 (25.2\%) & 30 (23.8\%) & $\begin{array}{l}114 \\
(21.9 \%)\end{array}$ & $\begin{array}{l}217 \\
(30.5 \%)\end{array}$ \\
\hline unknown & $\begin{array}{l}31 \\
(19.6 \%)\end{array}$ & $\begin{array}{l}25 \\
(13.4 \%)\end{array}$ & 18 (16.8\%) & $17(13.5 \%)$ & $\begin{array}{l}85 \\
(16.3 \%)\end{array}$ & $\begin{array}{l}100 \\
(14.0 \%)\end{array}$ \\
\hline \multicolumn{7}{|l|}{$\begin{array}{l}\text { Previous } \\
\text { chemotherapy }\end{array}$} \\
\hline no & $\begin{array}{l}127 \\
(80.4 \%)\end{array}$ & $\begin{array}{l}160 \\
(86.0 \%)\end{array}$ & 90 (84.1\%) & 105 (83.3\%) & $\begin{array}{l}430 \\
(82.7 \%)\end{array}$ & $\begin{array}{l}469 \\
(65.9 \%)\end{array}$ \\
\hline yes & $\begin{array}{l}31 \\
(19.6 \%)\end{array}$ & $\begin{array}{l}25 \\
(13.4 \%)\end{array}$ & 17 (15.9\%) & 21 (16.7\%) & $\begin{array}{l}90 \\
(17.3 \%)\end{array}$ & $\begin{array}{l}242 \\
(34.0 \%)\end{array}$ \\
\hline unknown & $0(\%)$ & $1(0.5 \%)$ & $0(\%)$ & $0(\%)$ & $0(\%)$ & $1(0.1 \%)$ \\
\hline
\end{tabular}

Objective responses according to exact primary tumor location and molecular subgroups

Generally, irrespective of exact therapy, objective response rates (ORR) according to exact primary tumor location were neither significantly different in the full population nor in molecular subgroups, although numerically higher response rates in left-sided exact locations may be observed in patients with $R A S / B R A F$ wildtype tumors as well as in BRAF mutant tumors. Rather low and homogeneous ORR ranging from $33 \%$ to $46 \%$ are observed in patients with RAS mutant mCRC when analyzed according to exact primary tumor location. Details are summarized in supplementary figure 3 . Response rates differed in molecular subgroups in general with $R A S / B R A F$ wildtype $\mathrm{mCRC}(60.5 \%)$ achieving higher rates as compared to RAS mutant mCRC (41.4\%) and BRAF mutant mCRC (42.2\%), $P<0.001$.

\section{Prognostic impact of exact primary tumor location}

In the analyzed population, the numerically longest PFS and OS are seen in patients with primary tumors located in the left flexure, descending colon and sigmoid. Among right-sided primaries no substantial differences were detected, despite primary tumors of right flexure/transverse colon $\mathrm{mCRC}$ trended to be associated with the numerically shortest survival. Kaplan Meier curves for all patients are indicated in Figure 1. Uni- and multivariate comparisons of exact primary tumor location with rectal primaries used as 
reference confirmed right flexure/transverse colon mCRC as the subgroups with the worst and clearly impaired prognosis in both uni- and multivariate analysis of overall survival. This finding appears to be driven by the two subgroups of patients with mutant mCRC (RAS and BRAF V600E). Please refer to Suppl. Figure 4 for details.

\section{Predictive impact of exact primary tumor location in patients with $R A S / B R A F$ wildtype and BRAF mutant tumors}

The predictive effect of exact primary tumor location for anti-EGFR was explored in uni- and multivariate analyses (Kaplan Meier estimates of overall survival in Figure 2; logistic and Cox regressions in Figure 3). ORR appeared to be influenced by exact primary tumor location with left sided locations being associated with a higher chance to achieve objective response to treatment. This observation was evident in both $R A S / B R A F$ wildtype mCRC as well as in BRAF mutant mCRC. Clear benefit with anti-EGFR antibodies in terms of ORR was notably seen in left-sided $\mathrm{mCRC}$ with $B R A F$ mutation in uni- as well as multivariate analyses.

In terms of PFS, a detrimental effect of anti-EGFR antibodies in patients with caecal RAS/BRAF wildtype mCRC as well as in patients caecal with $B R A F$ mutant $\mathrm{mCRC}$ was demonstrated, whereas no significant differences in all other segments were evident with rather neutral (trend towards benefit in BRAF mutant $\mathrm{mCRC}$ ) effects evolving with more distal primary tumor location. However, OS in RAS/BRAF wildtype mCRC appeared continuously improved with anti-EGFR antibodies the further distal the primary tumor was located. Whereas in patients with caecal primaries the usage of anti-EGFR antibodies resulted in a significant detrimental effect, neutral efficacy was seen in the continuity of the colon towards the sigmoid. The only subgroups demonstrating a clear benefit with anti-EGFR antibody treatment are patients with primaries located in sigmoid and rectal. Rectal PTL achieving the greatest benefit (hazard ratio for death: $0.58(95 \% \mathrm{Cl} 0.43-0.77))$. A similar pattern is observed in patients with $B R A F$ mutant mCRC. An exploratory analysis in left- and right-sided $B R A F$ mutant $\mathrm{mCRC}$ concerning anti-EGFR effects on OS suggests a significant benefit in favor of therapy with anti-EGFR antibodies in patients with leftsided, $B R A F$ mutant $\mathrm{mCRC}$. This is confirmed by both uni- and multivariate analysis and further confirmed by a significant interaction test ( $P$ for interaction=0.001). Please refer to Figures 2 and 3 for details. The interaction of PTL and anti-EGFR antibody efficacy is also present if the analysis is restricted to patients with $B R A F$ mutant tumors from FIRE-3 and VOLFI representing the purest population as they contained direct randomization of anti-EGFR-antibodies ( $P$ for interaction: 0.003 ). Kaplan Meier curves of the FIRE-3/VOLFI subset are shown as Suppl. Figure 5. No trends towards favourable outcomes with the use of anti-EGFR antibodies were observed in patients with RAS mutant mCRC (data not shown).

\section{Discussion}

The presented analysis based on five randomized trials including data from 1809 individual patients represents a large and robust basis to evaluate the prognostic and predictive effects of the exact primary tumor location in mCRC. 
Whereas the usual differentiation between left- vs. right colorectal cancer is a known predictor of OS in $\operatorname{mCRC}[1,4,22]$, our analysis suggests that certain differences between the exact segments may exist. Of interest, a clearly dismal prognosis (as compared to primary tumors of the rectum) was detected in patients with $\mathrm{mCRC}$ deriving from primaries of the right flexure/transverse colon. Similar trends of borderline significance in multivariate analyses were observed in patients with primaries in the caecum or ascending colon. Amongst patients with left-sided tumors, differences in outcome were not significantly different, although patients with rectal primaries appeared to achieve a numerically shorter OS as compared to patients with primaries of left flexure/descending colon and sigmoid. The small advantage of sigmoid vs. rectal carcinoma might be influenced by a smaller proportion of patients with RAS mutant mCRC in patients with sigmoid carcinoma ( $28 \%$ of tested specimens) as compared to patients with rectal cancer ( $42 \%$ of tested specimens) in context of a low frequency of BRAF V600E mutant tumors with dismal prognosis $[23,24]$ in both segments.

The effect of anti-EGFR antibodies did not impact on PFS in our cohort, illustrating - in accordance with previous publications - that PFS does not necessarily reflect the efficacy of these drugs $[19,25,26]$ and anti-EGFR antibodies may rather impact response related endpoints and OS [15, 19, 27-29].

Clear effects of exact primary tumor location on overall survival were observed in patients with $R A S / B R A F$ wildtype tumors. Interestingly, patients with primary tumors of the caecum derived a substantial disadvantage with anti-EGFR therapy, whereas substantial benefit was seen in patients with rectal cancers and - to a lesser extent - in patients with sigmoid primaries. Taken together, the data suggests a continuous increase of benefit from anti-EGFR antibodies from proximal (right) to distal (left) rather than the currently established dichotomous perspective of left (benefit from anti-EGFR) vs. right (no benefit from anti-EGFR) colorectal cancer [1,2]. This perspective is supported by molecular analysis of colorectal tumors that rather proposes a continuum of biological changes from proximal to distal segments of colon and rectum $[6,10]$. Based on these findings, treatment of rectal and sigmoid $R A S / B R A F$ wildtype $\mathrm{mCRC}$ with anti-EGFR-antibodies appears a clinical necessity. Particularly, mCRC patients with primaries in the rectum may achieve an enormous advantage with anti-EGFR-targeted therapy, and patients with $\mathrm{mCRC}$ with primaries in the sigmoid achieve a clinically relevant advantage.

Interestingly, in patients with $B R A F$ mutant $\mathrm{mCRC}$ a similar pattern of increasing anti-EGFR antibody therapy efficacy from proximal to distal was found in the segment by segment analysis. Whereas rightsided tumors achieved no benefit, left-sided tumors appeared to benefit from anti-EGFR therapy in our population. This finding was confirmed by a multivariate analysis and a significant interaction test.

The idea that left-sided $B R A F$ mutant tumors may respond to anti-EGFR treatment is further supported by an increased ORR and prolonged OS in the absence of clinically relevant effects on PFS in this data set. This combination has been frequently observed in an evidently anti-EGFR sensitive population (i.e. RAS/BRAF wildtype $\mathrm{mCRC})[1-3,19]$.

Therefore, it could be hypothesized that $B R A F$ mutation may not predict lack of anti-EGFR antibody efficacy. In turn, our findings suggest that patients with $B R A F$ mutant $\mathrm{mCRC}$ arising from left-sided 
primary tumors benefit to a similar extent from anti-EGFR antibodies as compared to RAS/BRAF wildtype tumors and should consecutively receive these drugs as part of first-line therapy. It needs to be noted that the sample size of this pooled analysis is too limited to draw definite conclusions on the benefit according to exact PTL (i.e. left flexure/descending colon, sigmoid and rectum).

Our findings are in contrast to reports that identified classical BRAF V600E mutations as likely negative predictors of anti-EGFR directed therapy [30-32]. However, it could be argued that these publications did not adjust their analyses for PTL and are consecutively biased by the relative over-representation of $B R A F$ mutations in right-sided colon segments [33], a circumstance that is also present in our population. Consecutively, current guideline recommendations [34] do not recommend anti-EGFR-targeted antibodies as part of first-line therapy and cetuximab is currently used rather as combination partner for a $B R A F$ inhibitor in refractory patients [35]. Accordingly, our finding in this particular subgroup challenges the actual treatment algorithm and needs confirmation from further trials with direct anti-EGFR-antibody randomisation such as CRYSTAL, PRIME, OPUS, CALGB/SWOG 80405 and PEAK [23, 36-38].

Challenging the idea of dichotomous left-right classification in $\mathrm{MCRC}$, our hypothesis of a continuous increase in anti-EGFR therapy related benefit from proximal to distal parts of the colorectum supports the idea that the underlying molecular equivalent is likely a non-dichotomous biomarker (combination), potentially including EGFR- ligands, HER-3 messenger RNA or miR-31-3p [39-42].

Our pooled analysis is limited by its retrospective and exploratory design as well as by the low patient numbers in segments of the colon with an overall low frequency of primary tumors. Furthermore, a pool of five studies (of those two directly randomizing the anti-EGFR antibody) using various treatment regimens and therefore, containing heterogeneous populations may have invoked potential undetected biases.

\section{Conclusions}

In our analysis, the exact primary tumor location of $\mathrm{MCRC}$ impacts prognosis and is also associated with increasing anti-EGFR efficacy in a continuous pattern from proximal to distal segments of the colorectum in patients with $R A S / B R A F$ wildtype tumors. Similarly, patients with $B R A F$ mutant mCRC originating from distal segments of the colorectum may benefit from first-line anti-EGFR-based therapy.

\section{List Of Abbreviations}

anti-EGFR, anti-epithelial growth factor receptor; anti-VEGFR, anti-vascular endothelial growth factor; $\mathrm{HR}$, hazard ratio; $\mathrm{MCRC}$, metastatic colorectal cancer; $\mathrm{OR}$, objective response; ORR, objective response rate; OS, overall survival; PFS, progression-free survival; PTL, primary tumor location.

\section{Declarations}

\section{Ethics approval and consent to participate}


All trials were conducted according to the Declaration of Helsinki and were approved by ethics committees.

\section{Consent for publication}

Not applicable

\section{Availability of data and materials}

The datasets used and/or analysed during the current study are available from the corresponding author on reasonable request.

\section{Competing interests}

\section{Annabel Helga Sophie Alig:}

Travel, Accommodations, Expenses: Pfizer, Roche, Eli Lilly, Novartis, PharmaMar

Consulting or Advisory Role: Roche

\section{Volker Heinemann:}

Honoraria: Roche, Celgene, Amgen, Sanofi, Merck, Sirtex Medical, Baxalta, Eli Lilly, Boehringer Ingelheim, Taiho Pharmaceutical, Servier

Consulting or Advisory Role: Merck, Amgen, Roche, Sanofi, Boehringer Ingelheim, Celgene, Sirtex Medical, Baxalta, Servier, Halozyme, MSD, Bristol-Myers Squibb

Research Funding: Merck (Inst), Amgen (Inst), Roche (Inst), Celgene (Inst), Boehringer Ingelheim (Inst), Sirtex Medical (Inst), Shire (Inst)

Travel, Accommodations, Expenses: Merck, Roche, Sirtex Medical, Amgen, Servier, Shire, MSD, BristolMyers Squibb

\section{Michael Geissler:}

Consulting or Advisory_Role: Amgen, Lilly, Merck and Serono

Travel, Accommodations, Expenses: Amgen

\section{Ludwig Fischer von Weikersthal:}

Honoraria: Novartis, Roche, Sanofi

Travel, Accommodations, Expenses: Amgen 
Consulting_or Advisory_Role: Novartis

Kathrin Heinrich:

Honoraria: Roche

Travel, Accommodations, Expenses: AMGEN, Celgene, Lilly

Swantje Held:

No conflicts of interest

Lena Weiss:

No conflicts of interest

Laura Elisabeth Fischer:

No conflicts of interest

Nicolas Moosmann:

No conflicts of interest

Arndt Stahler:

Honoraria: Roche

Travel, Accommodations, Expenses: Roche, Merck and Amgen

Ivan Jelas:

No conflicts of interest

Annika Kurreck:

Travel, Accommodations, Expenses: Roche, Medac

Jana Kaethe Striefler:

no conflicts of interest

Jobst Christian von Einem:

No conflicts of interest

Anke Claudia Reinacher-Schick: 
Honoraria: Amgen, Roche, Pfizer, Sanofi, Merck Serono, Shire, Celgene, Lilly, Bristol-Myers Squibb, Servier, Baxalta, Merck Sharp \& Dohme, Aurikamed, Bonita Pharmaceuticals, lomedico, $\mathrm{MCl}$ (managing meetings in cancer care and education), Med Publico, and Promedicis

Consulting or Advisory Role: Amgen, Roche, Pfizer, Sanofi, Merck Serono, Celgene, Bristol-Myers Squibb, Servier, Baxalta, Merck Sharp \& Dohme, and Onkowissen

Research Funding: Roche (Inst), Celgene (Inst), Ipsen (Inst), Amgen (Inst), Alexion (Inst), AstraZeneca (Inst), Lilly (Inst), Servier (Inst), Arbeitsgemeinschaft Internistische Onkologie Studien (Inst), Agricola (Inst), PPD Global Limited, UK (Inst), Mologen Berlin (Inst), Universität München (Inst), Universität Erlangen (Inst), Universität Köln (Inst), Pharma Consulting Group Schweden (Inst), and Syneed Medidata (Inst)

Travel, Accommodations, Expenses: Ipsen, Amgen, Celgene, Onkowissen, Roche, and Servier.

\section{Andrea Tannapfel}

Honoraria: Falk Foundation, Merck, Amgen, Pfizer, and Med Update; other: Pathohistologic testimonials for insurances.

\section{Clemens Giessen-Jung:}

Travel, Accommodations, Expenses: Roche

\section{Sebastian Stintzing:}

Honoraria: Merck, Roche, Amgen, Bayer, Sanofi, Sirtex Medical, Eli Lilly, Pierre-Fabre, Servier, Taiho Consulting or Advisory Role: Merck, Roche, Sanofi, Bayer, Amgen, Boehringer Ingelheim, Eli Lilly, Takeda, MSD, Pierre-Fabre

Travel,Accommodations, Expenses: Merck, Roche, Sanofi, Bayer, Sirtex Medical, Amgen, Eli Lilly, Takeda, Pierre Fabre

\section{Dominik Paul Modest:}

Honoraria: Merck Serono, Amgen, Roche, Servier, BMS, Pfizer, Sirtex Medical, MSD, Pierre Fabre, Onkowissen.de, Taiho, Sanofi, Eli Lilly

Consulting or Advisory Role: Merck Serono, Amgen, Bayer, Incyte, Servier, BMS, Onkowissen.de

Research Funding: Merck Serono (Inst), Roche (Inst), Amgen (Inst), Servier (Inst)

Travel,Accommodations, Expenses: Amgen, Merck Serono, Bayer, Servier, Bristol-Myers Squibb

\section{Funding}


The hospital of the university (LMU) was the legal sponsor of FIRE-1 (supported by Pfizer), CIOX (supported by Merck- Darmstadt; Roche and Pfizer), FIRE-3 (supported by Merck- Darmstadt and Pfizer) and XELAVIRI (supported by Roche). The AIO Studien gGmbH was the legal sponsor of VOLFI (supported by Amgen). The supporting parties had no role in the design, analyses or decision to submit the data for publication.

\section{Authors' contributions:}

Conception and design: AHSA, VH, SS, DPM

Administrative support: SH

Provision of study material or patients: VH, MG, LFvW, TD, AS, NM, ACRS, CGJ, SS, DPM

Collection and assembly of data: AHSA, VH, MG, LFvW, TD, AS, NM, ACRS, CGJ, SS, DPM

Data analysis and interpretation: All authors

Manuscript writing: All authors

Final approval of manuscript: All authors

Accountable for all aspects of the work: All authors

\section{Acknowledgements}

The authors thank all participating patients and their loved ones, all study investigators and their staff.

\section{References}

1. Arnold D, Lueza B, Douillard JY et al. Prognostic and predictive value of primary tumour side in patients with RAS wild-type metastatic colorectal cancer treated with chemotherapy and EGFR directed antibodies in six randomized trials. Ann Oncol 2017; 28: 1713-1729.

2. Holch JW, Ricard I, Stintzing $S$ et al. The relevance of primary tumour location in patients with metastatic colorectal cancer: A meta-analysis of first-line clinical trials. Eur J Cancer 2017; 70: 87-98.

3. Tejpar S, Stintzing S, Ciardiello F et al. Prognostic and Predictive Relevance of Primary Tumor Location in Patients With RAS Wild-Type Metastatic Colorectal Cancer: Retrospective Analyses of the CRYSTAL and FIRE-3 Trials. JAMA Oncol 2016.

4. Modest DP, Schulz C, von Weikersthal LF et al. Outcome of patients with metastatic colorectal cancer depends on the primary tumor site (midgut vs. hindgut): analysis of the FIRE1-trial (FuFIRI or mIROX as first-line treatment). Anticancer Drugs 2014; 25: 212-218.

5. Stintzing S, Wirapati P, Lenz HJ et al. Consensus molecular subgroups (CMS) of colorectal cancer (CRC) and first-line efficacy of FOLFIRI plus cetuximab or bevacizumab in the FIRE3 (AIO KRK-0306) 
trial. Ann Oncol 2019; 30: 1796-1803.

6. Yamauchi M, Morikawa T, Kuchiba A et al. Assessment of colorectal cancer molecular features along bowel subsites challenges the conception of distinct dichotomy of proximal versus distal colorectum. Gut 2012; 61: 847-854.

7. Stahler A, Stintzing S, von Einem JC et al. Single-nucleotide variants, tumour mutational burden and microsatellite instability in patients with metastatic colorectal cancer: Next-generation sequencing results of the FIRE-3 trial. Eur J Cancer 2020; 137: 250-259.

8. Fontana E, Nyamundanda G, Cunningham D et al. Intratumoral Transcriptome Heterogeneity Is Associated With Patient Prognosis and Sidedness in Patients With Colorectal Cancer Treated With Anti-EGFR Therapy From the C0.20 Trial. JCO Precis Oncol 2020; 4.

9. Lenz HJ, Ou FS, Venook AP et al. Impact of Consensus Molecular Subtype on Survival in Patients With Metastatic Colorectal Cancer: Results From CALGB/SWOG 80405 (Alliance). J Clin Oncol 2019; 37: 1876-1885.

10. Loree JM, Pereira AAL, Lam M et al. Classifying Colorectal Cancer by Tumor Location Rather than Sidedness Highlights a Continuum in Mutation Profiles and Consensus Molecular Subtypes. Clin Cancer Res 2018; 24: 1062-1072.

11. Fischer von Weikersthal L, Schalhorn A, Stauch M et al. Phase III trial of irinotecan plus infusional 5fluorouracil/folinic acid versus irinotecan plus oxaliplatin as first-line treatment of advanced colorectal cancer. Eur J Cancer 2011; 47: 206-214.

12. Heinemann V, von Weikersthal LF, Decker T et al. FOLFIRI plus cetuximab versus FOLFIRI plus bevacizumab as first-line treatment for patients with metastatic colorectal cancer (FIRE-3): a randomised, open-label, phase 3 trial. Lancet Oncol 2014; 15: 1065-1075.

13. Modest DP, Fischer von Weikersthal L, Decker T et al. Sequential Versus Combination Therapy of Metastatic Colorectal Cancer Using Fluoropyrimidines, Irinotecan, and Bevacizumab: A Randomized, Controlled Study-XELAVIRI (AIO KRK0110). J Clin Oncol 2019; 37: 22-32.

14. Modest DP, Jung A, Moosmann $\mathrm{N}$ et al. The influence of KRAS and BRAF mutations on the efficacy of cetuximab-based first-line therapy of metastatic colorectal cancer: an analysis of the AIO KRK0104-trial. Int J Cancer 2012; 131: 980-986.

15. Modest DP, Martens UM, Riera-Knorrenschild J et al. FOLFOXIRI Plus Panitumumab As First-Line Treatment of RAS Wild-Type Metastatic Colorectal Cancer: The Randomized, Open-Label, Phase II VOLFI Study (AIO KRK0109). J Clin Oncol 2019; 37: 3401-3411.

16. Moosmann $\mathrm{N}$, von Weikersthal LF, Vehling-Kaiser $\mathrm{U}$ et al. Cetuximab plus capecitabine and irinotecan compared with cetuximab plus capecitabine and oxaliplatin as first-line treatment for patients with metastatic colorectal cancer: AIO KRK-0104-a randomized trial of the German AIO CRC study group. J Clin Oncol 2011; 29: 1050-1058.

17. Stahler A, Heinemann V, Giessen-Jung $C$ et al. Influence of mRNA expression of epiregulin and amphiregulin on outcome of patients with metastatic colorectal cancer treated with 5-FU/LV plus 
irinotecan or irinotecan plus oxaliplatin as first-line treatment (FIRE 1-trial). Int J Cancer 2016; 138 : 739-746.

18. Stintzing S, Fischer von Weikersthal L, Decker T et al. FOLFIRI plus cetuximab versus FOLFIRI plus bevacizumab as first-line treatment for patients with metastatic colorectal cancer-subgroup analysis of patients with KRAS: mutated tumours in the randomised German AIO study KRK-0306. Ann Oncol 2012; 23: 1693-1699.

19. Stintzing S, Modest DP, Rossius $L$ et al. FOLFIRI plus cetuximab versus FOLFIRI plus bevacizumab for metastatic colorectal cancer (FIRE-3): a post-hoc analysis of tumour dynamics in the final RAS wild-type subgroup of this randomised open-label phase 3 trial. Lancet Oncol 2016; 17: 1426-1434.

20. Stintzing S, Miller-Phillips L, Modest DP et al. Impact of BRAF and RAS mutations on first-line efficacy of FOLFIRI plus cetuximab versus FOLFIRI plus bevacizumab: analysis of the FIRE-3 (AIO KRK-0306) study. Eur J Cancer 2017; 79: 50-60.

21. Heinemann V, von Weikersthal LF, Decker T et al. FOLFIRI plus cetuximab or bevacizumab for advanced colorectal cancer: final survival and per-protocol analysis of FIRE-3, a randomised clinical trial. Br J Cancer 2020.

22. Tejpar S, Celik I, Schlichting M et al. Association of KRAS G13D tumor mutations with outcome in patients with metastatic colorectal cancer treated with first-line chemotherapy with or without cetuximab. J Clin Oncol 2012; 30: 3570-3577.

23. Innocenti F, Ou FS, Qu X et al. Mutational Analysis of Patients With Colorectal Cancer in CALGB/SWOG 80405 Identifies New Roles of Microsatellite Instability and Tumor Mutational Burden for Patient Outcome. J Clin Oncol 2019; 37: 1217-1227.

24. Modest DP, Ricard I, Heinemann V et al. Outcome according to KRAS-, NRAS- and BRAF-mutation as well as KRAS mutation variants: pooled analysis of five randomized trials in metastatic colorectal cancer by the AIO colorectal cancer study group. Ann Oncol 2016; 27: 1746-1753.

25. Venook AP, Tabernero J. Progression-free survival: helpful biomarker or clinically meaningless end point? J Clin Oncol 2015; 33: 4-6.

26. Giessen C, Laubender RP, Ankerst DP et al. Progression-free survival as a surrogate endpoint for median overall survival in metastatic colorectal cancer: literature-based analysis from 50 randomized first-line trials. Clin Cancer Res 2013; 19: 225-235.

27. Khattak MA, Martin H, Davidson A, Phillips M. Role of first-line anti-epidermal growth factor receptor therapy compared with anti-vascular endothelial growth factor therapy in advanced colorectal cancer: a meta-analysis of randomized clinical trials. Clin Colorectal Cancer 2015; 14: 81-90.

28. Piessevaux $H$, Buyse $M$, Schlichting $M$ et al. Use of early tumor shrinkage to predict long-term outcome in metastatic colorectal cancer treated with cetuximab. J Clin Oncol 2013; 31: 3764-3775.

29. Douillard JY, Siena S, Peeters M et al. Impact of early tumour shrinkage and resection on outcomes in patients with wild-type RAS metastatic colorectal cancer. Eur J Cancer 2015; 51: 1231-1242.

30. Pietrantonio F, Petrelli F, Coinu A et al. Predictive role of BRAF mutations in patients with advanced colorectal cancer receiving cetuximab and panitumumab: a meta-analysis. Eur J Cancer 2015; 51: 
587-594.

31. Di Nicolantonio F, Martini M, Molinari F et al. Wild-type BRAF is required for response to panitumumab or cetuximab in metastatic colorectal cancer. J Clin Oncol 2008; 26: 5705-5712.

32. De Roock W, Claes B, Bernasconi D et al. Effects of KRAS, BRAF, NRAS, and PIK3CA mutations on the efficacy of cetuximab plus chemotherapy in chemotherapy-refractory metastatic colorectal cancer: a retrospective consortium analysis. Lancet Oncol 2010; 11: 753-762.

33. Tran B, Kopetz S, Tie J et al. Impact of BRAF mutation and microsatellite instability on the pattern of metastatic spread and prognosis in metastatic colorectal cancer. Cancer 2011; 117: 4623-4632.

34. Van Cutsem E, Cervantes A, Adam R et al. ESMO consensus guidelines for the management of patients with metastatic colorectal cancer. Ann Oncol 2016; 27: 1386-1422.

35. Kopetz S, Grothey A, Yaeger R et al. Encorafenib, Binimetinib, and Cetuximab in BRAF V600E-Mutated Colorectal Cancer. N Engl J Med 2019; 381: 1632-1643.

36. Bokemeyer $C$, Van Cutsem E, Rougier $P$ et al. Addition of cetuximab to chemotherapy as first-line treatment for KRAS wild-type metastatic colorectal cancer: pooled analysis of the CRYSTAL and OPUS randomised clinical trials. Eur J Cancer 2012; 48: 1466-1475.

37. Douillard JY, Oliner KS, Siena S et al. Panitumumab-FOLFOX4 treatment and RAS mutations in colorectal cancer. N Engl J Med 2013; 369: 1023-1034.

38. Schwartzberg LS, Rivera F, Karthaus M et al. PEAK: A Randomized, Multicenter Phase II Study of Panitumumab Plus Modified Fluorouracil, Leucovorin, and Oxaliplatin (mFOLFOX6) or Bevacizumab Plus mFOLFOX6 in Patients With Previously Untreated, Unresectable, Wild-Type KRAS Exon 2 Metastatic Colorectal Cancer. J Clin Oncol 2014.

39. Seligmann JF, Elliott F, Richman SD et al. Combined Epiregulin and Amphiregulin Expression Levels as a Predictive Biomarker for Panitumumab Therapy Benefit or Lack of Benefit in Patients With RAS Wild-Type Advanced Colorectal Cancer. JAMA Oncol 2016; 2: 633-642.

40. Seligmann JF, Hatch AJ, Richman SD et al. Association of Tumor HER3 Messenger RNA Expression With Panitumumab Efficacy in Advanced Colorectal Cancer. JAMA Oncol 2018; 4: 564-568.

41. Stahler A, Stintzing S, Modest DP et al. Amphiregulin expression is a predictive biomarker for EGFR inhibition in metastatic colorectal cancer: combined analysis of three randomized trials. Clin Cancer Res 2020.

42. Laurent-Puig P, Grisoni ML, Heinemann V et al. Validation of miR-31-3p Expression to Predict Cetuximab Efficacy When Used as First-Line Treatment in RAS Wild-Type Metastatic Colorectal Cancer. Clin Cancer Res 2019; 25: 134-141.

\section{Figures}




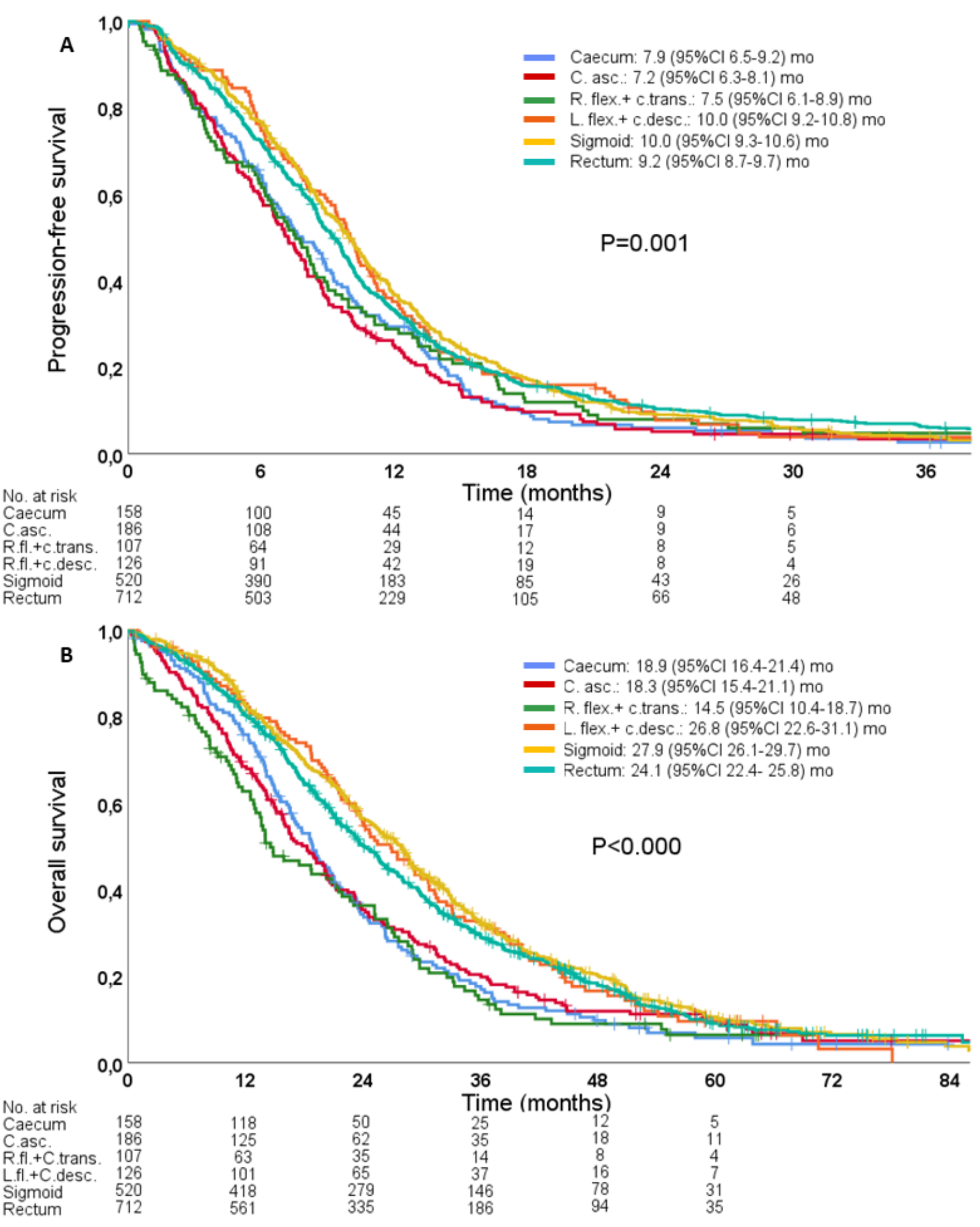

\section{Figure 1}

Kaplan Meier estimates of progression-free survival and overall survival according to exact PTL Legend: A) progression-free survival, B) Overall survival. C. asc.= ascending colon, r. flex./r.fl.=right flexure, I. flex/l.fl.=left flexure, c. trans=transverse colon, c. desc.=descending colon. P-values: log rank test. 

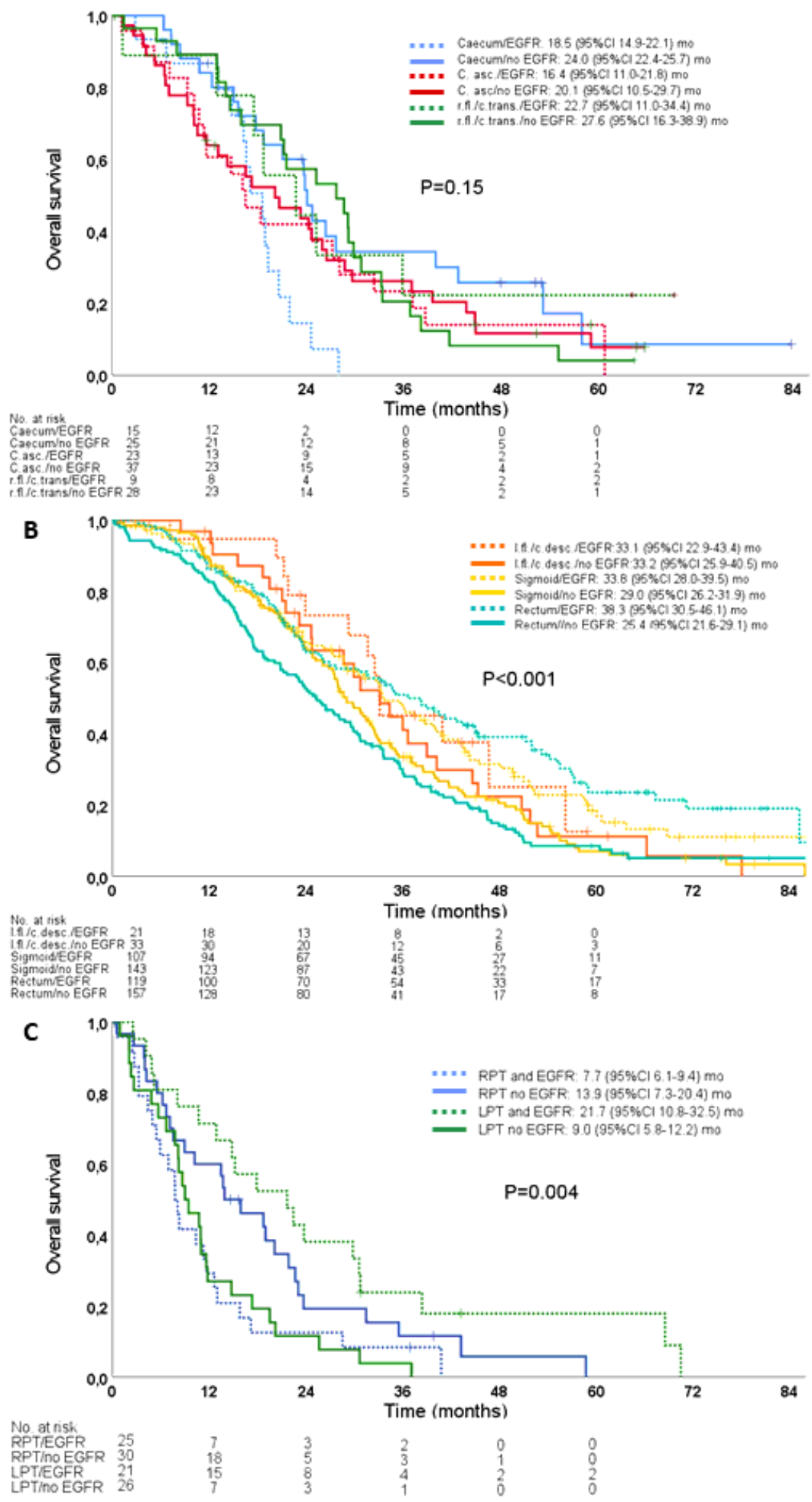

\section{Figure 2}

Kaplan Meier estimates of overall survival according to use of EGFR antibodies stratified by PTL Legend: A) RAS/BRAF WT right-sided primary tumor locations by EGFR-mAb use B) RAS/BRAF WT left-sided primary tumor locations by EGFR-mAb use, C) BRAF MT left- vs- right primary tumors by EGFR-mAb use. 


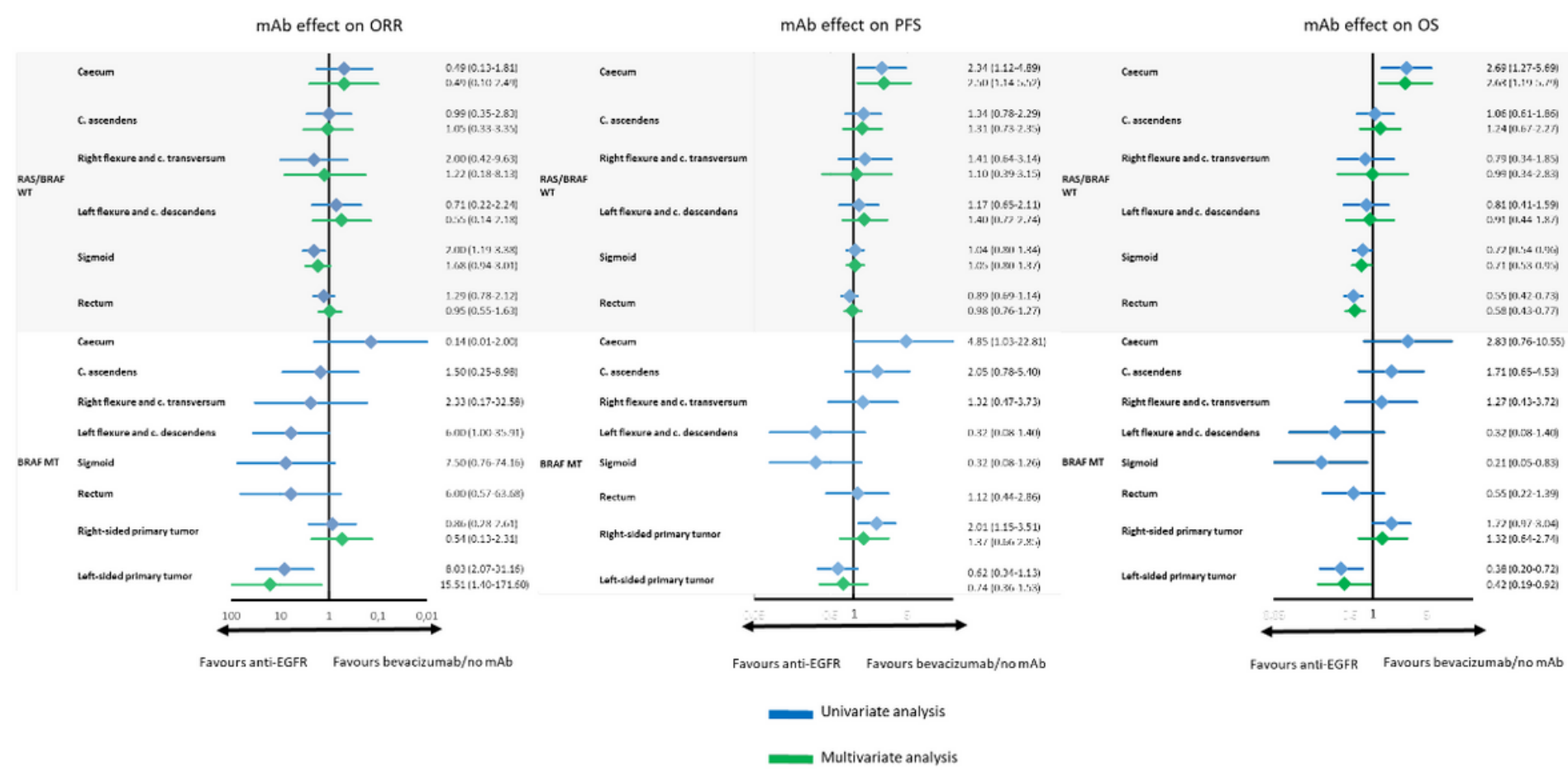

\section{Figure 3}

Forest plots of estimated anti-EGFR effect according to exact primary tumor location Legend: Uni- and multivariate analyses of anti-EGFR effect. Segment by segment analyses in patients with BRAF mutant mCRC were not performed due to insufficient numbers and resulting low fit of the models. Multivariate analyses of progression-free survival and overall survival included as factors: study, sex, age, ECOG performance status, liver-limited disease, peritoneal metastasis, prior adjuvant chemotherapy.

Multivariate analyses of objective response rate included sex, age, ECOG performance status, liver-limited disease, peritoneal metastasis, prior adjuvant chemotherapy. ORR=objective response rate; $\mathrm{PFS}=$ progression free survival; OS=overall survival; $\mathrm{mAb}=$ monoclonal antibody

\section{Supplementary Files}

This is a list of supplementary files associated with this preprint. Click to download.

- suppl.FIGURE1.docx

- suppl.FIGURE2.docx

- suppl.FIGURE3.docx

- suppl.FIGURE4.docx

- suppl.FIGURE5.docx

- SupplementaryTable.docx 